\title{
O LUGAR OCUPADO PELA AVALIAÇÃO DA APRENDIZAGEM NA FORMAÇÃO DO PROFESSOR DO CURSO DE DIREITO
}

\author{
Carla Priscilla Barbosa Santos Cordeiro ${ }^{1}$, Edna Cristina do Prado $^{2}$, Lana Lisiêr de Lima Palmeira ${ }^{3}$ \\ ${ }^{1}$ Doutora em Educação Universidade Federal de Alagoas - UFAL. Professora do Centro Universitário CESMAC, AL. \\ ORCID iD: https://orcid.org/0000-0002-2806-6023. E-mail: carlapriscilla@cesmac.edu.br \\ ${ }^{2}$ Pós-doutorado em Educação no Instituto de Educação da Universidade de Lisboa -(IE/UL; Doutorado em Educação \\ Escolar pela Universidade Estadual Paulista Júlio de Mesquita Filho - UNESP. Professora da Universidade Federal de \\ Alagoas - UFAL, AL. ORCID iD: https://orcid.org/0000-0001-8226-2466. E-mail: wiledna@uol.com.br \\ ${ }^{3}$ Doutora em Educação Universidade Federal de Alagoas - UFAL. Professora da Universidade Federal de Alagoas - \\ UFAL, AL. ORCID iD: https://orcid.org/0000-0003-0443-7245. E-mail: lanallpalmeira@outlook.com
}

\section{RESUMO}

Este artigo analisa o lugar ocupado pela avaliação da aprendizagem na formação do professor do curso de Direito. Seu objetivo principal é compreender o conceito de avaliação, a forma como a legislação prevê a sua realização e como os programas de pós-graduação sricto sensu incluem a avaliação na formação dos professores que atuarão no magistério jurídico. A pesquisa possui natureza quanti-qualitativa e foi realizada a partir de análise bibliográfica e documental. A avaliação da aprendizagem é analisada a partir de estudiosos da área, como Perrenoud (1999), Rodrigues (1999), Vianna (2000), Haydt (2004), Lafoucade (2010), Romão (2011) e Hoffmann (2014), tornando possível a compreensão de seu caráter processual e dialético. Realizou-se um estudo sobre as ementas das disciplinas constantes dos programas de pósgraduação em Direito no Nordeste brasileiro, a fim de investigar se existem disciplinas voltadas à formação docente e se elas abarcam o estudo da avaliação. Como resultado, foi possível perceber que a formação para a docência nesses cursos possui grandes deficiências e que a avaliação ocupa a periferia dos currículos desses programas, sendo vista apenas em 3 (três) disciplinas das matrizes curriculares das 16 (dezesseis) Instituições de Ensino Superior (IES) analisadas.

Palavras-chave: Avaliação. Ensino. Direito. Legislação. Formação Docente.

\section{THE PLACE OCCUPIED BY THE LEARNING ASSESSMENT IN THE TRAINING OF THE LAW COURSE TEACHER}

\section{ABSTRACT}

This article analyzes the place occupied by the learning assessment in the formation of the professor of the law course. Its main objective is to understand the concept of evaluation, the way in which the legislation provides for its realization and how the stricto sensu postgraduate programs include evaluation in the training of teachers who will work in the legal teaching. The research has a quantitative and qualitative nature and was carried out based on bibliographic and documentary analysis. Evaluation of learning is analyzed from scholars in the field, such as Perrenoud (1999), Rodrigues (1999), Vianna (2000), Haydt (2004), Lafoucade (2010), Romão (2011) and Hoffmann (2014), making it possible to understand its procedural and dialectical character. A study was carried out on the syllabuses of the disciplines included in the graduate programs in Law in Brazilian Northeast, to investigate whether there are courses aimed at training teachers and they cover the evaluation study. As a result, it was possible to realize that the training for teaching in these courses has great deficiencies and that the evaluation occupies the periphery of the curricula of these programs, being seen only in 3(three) disciplines of the curricular matrices of the 16 (sixteen) Higher Education Institutions (HEIs) analyzed.

Keywords: Evaluation. Teaching. Right. Legislation. Teacher Training. 


\section{EL LUGAR OCUPADO POR LA EVALUACIÓN DE APRENDIZAJE EN LA CAPACITACIÓN DEL PROFESOR DEL CURSO DE DERECHO}

\section{RESUMEN}

Este artículo analiza el lugar que ocupa la evaluación del aprendizaje en la formación de docentes Derecho. Su objetivo principal es comprender el concepto de evaluación, la forma en que la legislación prevé su realización y cómo los programas de posgrado stricto sensu incluyen la evaluación en la formación de maestros que van a trabajar como profesores de derecho. La investigación tiene un carácter cuantitativo y cualitativo y se realizó en base a análisis bibliográfico y documental. La evaluación del aprendizaje es analizada por académicos en el campo, como Perrenoud (1999), Rodrigues (1999), Vianna (2000), Haydt (2004), Lafoucade (2010), Romão (2011) y Hoffmann (2014), tornando possível a compreensão de seu caráter processual e dialético. Se realizó un estudio sobre los programas de estudio de las disciplinas incluidas en los programas de posgrado en Derecho en el Nordeste brasileño, para investigar si existen disciplinas dirigidas a la formación del profesorado y si abarcan el estudio de la evaluación. Como resultado, fue posible notar que la formación docente en estos cursos tiene grandes deficiencias y que la evaluación ocupa la periferia de los planes de estudio de estos programas, siendo observada solo en 3 (tres) de las matrices curriculares de las 16 (dieciséis) instituciones de educación superior (IES) analizadas.

Palabras clave: Evaluación. Enseñando. Derecho. Legislación. Formación del Profesorado.

\section{INTRODUÇÃO}

Este artigo analisa o lugar ocupado pela avaliação da aprendizagem na formação para o magistério superior nos cursos de Direito, a partir da análise da existência de disciplinas em programas de mestrado e doutorado em Direito no Nordeste brasileiro que contemplassem disciplinas voltadas à atuação em sala de aula, no ano de 2020.

Como questão central desta pesquisa, busca-se compreender qual o local ocupado pela avaliação da aprendizagem nos cursos de pósgraduação stricto sensu em Direito no Nordeste. Parte-se do pressuposto de que a avaliação do ensino e aprendizagem é um dos pontos mais frágeis dos problemas inerentes ao ensino jurídico. Trata-se de um tema que não tem sido debatido dentro das faculdades de Direito porque ainda prevalecem várias das tradições históricas que resumem a avaliação à aplicação de exames para fins de aferição da quantidade de conhecimento que foi apreendido pelos estudantes, tomando-se como parâmetro o programa de curso sob a ótica do professor (CAPELLARI, 2001; MURARO, 2010).

Mesmo com os avanços científicos em todas as áreas, a relação entre ensino do Direito e Pedagogia e a Andragogia, permanece debilitada (PRADO, 2015), pois a avaliação do ensino e aprendizagem ainda se reveste de um instrumento de classificação e exclusão social dentro dos próprios cursos.

Em vez de servir como uma forma de melhorar o processo de ensino e aprendizagem, a avaliação nos cursos jurídicos reitera um modelo de ensino ultrapassado, corroborando sua precarização no quadro do ensino superior brasileiro. Por isso, essa temática foi escolhida como objeto desta pesquisa, uma vez que se tornou urgente a necessidade de ressignificar essa prática.

Este estudo se debruça sobre o local ocupado pela avaliação da aprendizagem na formação para atuação no magistério superior nos cursos de Direito, objetivando-se compreender as exigências legais mínimas para a formação do professor desta área. Como objetivos específicos, busca-se analisar como ocorre essa formação nos cursos de pósgraduação stricto sensu no Nordeste, por meio da verificação da presença de disciplinas relacionadas à prática da sala de aula, tal como avaliação da aprendizagem. Além disso, procurase compreender possíveis caminhos para a melhoria da atuação docente para que a prática da avaliação da aprendizagem tradicional nos cursos de Direito seja superada.

Com natureza quanti-qualitativa, este estudo se constitui por uma pesquisa bibliográfica (a partir da análise de autores que estudaram a temática da avaliação da aprendizagem nos últimos anos) e documental (o que se deu com a análise de documentos dos cursos de pós-graduação stricto sensu no Nordeste).

A pesquisa que embasa esta produção foi 
realizada com a análise dos dados da CAPES de 2018 sobre as pós-graduações stricto sensu em Direito no Nordeste, bem como nas informações públicas que esses programas disponibilizaram em suas plataformas on line. Ao todo, foram analisados 23 programas. Confrontaram-se os dados obtidos por meio da triangulação das pesquisas bibliográficas e documental.

A análise qualitativa se preocupou em compreender como deve ocorrer a formação para o magistério superior de Direito, bem como qual o papel ocupado pela avaliação da aprendizagem na formação e práxis docente.

O estudo teve como fundamentos autores que se debruçaram sobre a avaliação da aprendizagem, em seu caráter processual; a formação de professores para atuação no ensino superior e as deficiências no ensino jurídico, como Rodrigues (1993), Adeodato (1999), Castro (2004), Morais e Santos (2007), Machado (2009), Muraro (2010), Abikair Neto (2014), Prado (2015), Palmeira (2018) e Cordeiro (2019).

$\mathrm{O}$ artigo, além da introdução e conclusão, divide-se em três seções. A primeira apresenta o conceito de avaliação da aprendizagem e as principais visões de autores que estudam a temática. A segunda analisa como a avaliação da aprendizagem está prevista na legislação pátria, a fim de compreender as obrigações dos professores, IES e do próprio Estado. A terceira e última seção faz um estudo da formação do professor dos cursos superiores de Direito nos mestrados e doutorados no Nordeste, lançando um olhar por possíveis caminhos que podem ser trilhados para superar a visão tradicional da avaliação da aprendizagem que ainda é percebida nesses cursos.

\section{AVALIAÇÃO DA APRENDIZAGEM}

A palavra "avaliação" remete a vários tipos diferentes de compreensão ou medida de algo. Realiza-se a avaliação dos fatos do dia a dia o todo tempo, o que ocorre de maneira muito espontânea, com pouco ou nenhum planejamento, como é o caso dos julgamentos morais realizados pelos indivíduos em diversas instâncias sociais. De outro lado, existem os procedimentos em que a avaliação é vista como instrumento formal, institucionalizada em diversos ambientes públicos e privados com 0 objetivo de se realizar a aferição de algum dado, resultado, opinião etc. Ainda há que se falar da avaliação como um instrumento que pertence, por excelência, ao cotidiano escolar, gerando, por vezes, a ideia errônea de ser mesmo o objetivo final da aprendizagem, que deveria ser medida em testes e provas no geral.

Rodrigues (1999) explica que a avaliação pode ser vista de diferentes ângulos: dos alunos; dos sistemas educativos e de inovação; dos professores e dos currículos. Desta maneira, ao mencionar a avaliação dos alunos, refere-se à observação de como ocorre o processo de aprendizagem e a produção de conhecimentos. De outro lado, pontua que é possível avaliar, nos sistemas educativos e da inovação, tudo aquilo que vai além do processo de aprendizagem, como os cursos em si, os métodos educativos, políticas educacionais, currículos etc. É possível, também, estudar o aspecto docente, que vai das características de sua personalidade até a forma como ele conduziu o processo educativo. $O$ autor enfatiza a avaliação curricular como um processo auxiliar à avaliação do ensino e aprendizagem, pois considera que a fixação de objetivos prévios ao ensino, relacionados ao currículo, é tão importante quanto o processo em si de avaliação, pois é a partir deles que se torna possível atestar se houve ou não a construção do aprendizado dos conteúdos e habilidades pretendidas ao curso.

Desta maneira, ao se falar em avaliar, genericamente, muitas possibilidades podem vir à tona, uma vez que é possível afirmar que quem avalia tenta observar a realidade a partir de um determinado prisma, buscando satisfazer a uma dada proposta ou interesse, para atestar a um fato ou conjunto de fatos dessa mesma realidade, o que pode ser aplicado a órgãos ou repartições públicas, entidades privadas, organizações sem finalidade lucrativa, ao ensino em escolas ou universidades, dentre tantas outras possibilidades. Por isso, não é incomum que o termo possa gerar confusões conceituais, pois pode se referir a qualquer área que envolva alguma espécie de atuação humana. É sob esta ótica que alguns dos teóricos que se debruçam sobre a temática a conceituam de inúmeras maneiras.

Trata-se de um dos momentos mais importantes do processo educacional, pois, a partir dela, é possível compreender as peculiaridades do ensino, ou seja, perceber como a ação educativa ocorreu na prática, a partir da identificação dos conteúdos, conceitos e visões que foram apreendidas pelos discentes em sala de aula. Ela pode e deve, para além disso, ser utilizada como um potente instrumento de 
geração de novos conhecimentos pelo aluno, com um propósito emancipador e não com o mero intuito de classificar, rotular ou selecionar indivíduos. Por isso, seu estudo se tornou uma importante pauta para o ensino superior brasileiro, que passa, hoje, por uma evidente necessidade de reformas que melhorem a qualidade neste nível de educação.

Presente na vida alunos e professores, a avaliação deve ser encarada como um momento de grande reflexão, pois permite, de um lado, que estes observem como a construção do conhecimento aconteceu para cada aluno, aproveitando a oportunidade para melhorar sua atuação docente e corrigir eventuais falhas ou dificuldades que os seus alunos possam ter tido. Não pode ser realizada de qualquer maneira, sem o adequado planejamento, pois precisa seguir procedimentos e etapas específicas a depender do tipo de conhecimento que se deseja produzir dentro da escola ou universidade. Por isso, compreender seu conceito, as teorias que the fundamentam, tipos, formas de realização, dentre outras coisas, torna-se essencial a quem deseja atuar no magistério de qualquer área. Neste sentido, pontua Vianna (2000, p. 29-30):

A atividade do avaliador
torna-se bastante
complexa, exigindo o
emprego de técnicas
sofisticadas, quando se
considera que um
construto precisa ser
comparado a outros para
que se possa determinar
se o novo construto
representa, efetivamente,
algum avanço em relação
ao anterior; por outro
lado, é preciso testar a
aplicabilidade de suas
conclusões na explicação
dos fenômenos e
comparar o constructo a
outros anteriormente
comprovados confirmando
sua veracidade ou
positivando sua falsidade.
O problema implícito, no
campo da avaliação,
estaria na comprovação da
validade ou dos
instrumentos que
supostamente estariam
medindo ou características
definidas nos constructos.

Percebe-se, desta maneira, que a realização da avaliação passa pela compreensão de procedimentos específicos, que irão variar a cada tipo de ensino que se pretende. Por isso, a formação de quem pretende utilizar a avaliação para realizar qualquer tipo de análise, em um contexto educacional, de nível escolar ou universitário, passa pela esfera pedagógica.

É preciso reconhecer que existem vários conceitos para a avaliação. A intensa produção teórica, principalmente da década de 1950 até os dias atuais, legou a esta área da ciência imenso portfólio de práticas que podem ser realizadas ao longo do processo de ensino e aprendizagem. Neste sentido, conceitos variados podem ser identificados à avaliação, como pode ser visto a partir de alguns dos importantes teóricos contemporâneos que estudam a temática:

A avaliação é entendida aqui como uma etapa do processo educacional que tem por fim comprovar, de modo sistemático, em que medida se alcançam os resultados pelos objetivos especificados com antecedência (LAFOUCADE, 2010, p. 18).

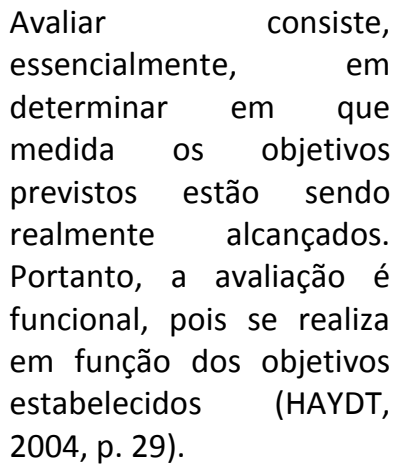

A avaliação do ensino e aprendizagem é o procedimento docente que atribui símbolos a fenômenos cujas dimensões foram medidas, a fim de lhes caracterizar o valor, por comparação com padrões prefixados (ROMÃO, 2011, p. 83-84).

São inúmeras as visões que norteiam o conceito de avaliação. Neste sentido, após Haydt (2004, p. 13-14) analisar os estudos de teóricos como Scriven, Stufflebeam, Bloom, Hastings e 
Madaus, afirma que a avaliação segue alguns princípios básicos, a partir de uma dimensão orientadora:

* É um processo contínuo e sistemático. Portanto, ela não pode ser esporádica nem improvisada, mas, ao contrário, deve ser constante e planejada. Nessa perspectiva, a avaliação faz parte de um sistema mais amplo que é o processo de ensinoaprendizagem, nele se integrando. Como tal, ela deve ser planejada para ocorrer normalmente ao longo de todo esse processo, fornecendo feedback e permitindo a recuperação imediata quando for necessário.

* A avaliação é funcional, porque se realiza em função de objetivos. Avaliar o processo ensinoaprendizagem consiste em verificar em que medida os alunos estão atingindo os objetivos previstos. Por isso, os objetivos constituem o elemento norteador da avaliação.

* A avaliação é orientadora, pois "não visa eliminar alunos, mas orientar seu processo de aprendizagem para que possam atingir os objetivos previstos". Nesse sentido, a avaliação permite ao aluno conhecer seus erros e acertos, auxiliando-o a fixar as respostas corretas e a corrigir as falhas.

* A avaliação é integral, pois analisa e julga todas as dimensões do comportamento,

considerando $o$ aluno como um todo. Desse modo, ela incide não apenas sobre os elementos cognitivos, mas também sobre o aspecto afetivo e o domínio psicomotor. (HAYDT, 2004, p. 13-14).

Percebe-se, com isso, que não se trata de um processo que, a priori, se esgota em um único momento. Ao contrário, exige reflexão, planejamento, procedimentos adequados para sua realização, escolha de instrumentos avaliativos, análise de dados, análise de resultados, ação transformadora, dentre outras etapas. Não pode ser realizada de qualquer modo, uma vez que uma ação descoordenada de objetivos pedagógicos perde toda a essência do processo educativo.

\subsection{A VISÃO POSITIVISTA DA AVALIAÇÃO}

A avaliação é reconhecida, tradicionalmente, como um processo classificatório e hierarquizador por natureza, que serve a finalidade social de identificar nos indivíduos competências, habilidades e conhecimentos que são úteis e essenciais a um dado sistema. Sobre o assunto, Romão (2011) aponta que é muito comum, entre os teóricos brasileiros que abordam a temática da avaliação do ensino e aprendizagem, essa visão que chama de "positivista". Nela, é dada ênfase a uma série de processos que visam quantificar o aprendizado do aluno, e, por isso, docentes que adotam essa posição evitam, muitas vezes, avaliar os alunos sobre um prisma subjetivo, dado o fato que isso poderia contaminar a verificação direta $e$ quantitativa da aprendizagem. Para embasar a análise do desempenho dos alunos, o professor que leciona sob o prisma do positivismo geralmente adota teorias e pontos de vista que sejam aceitos universalmente.

Seguindo o mesmo raciocínio, Romão (2011) afirma que se existe, dentre os teóricos que abordam a temática da avaliação, os positivistas, de outro lado, existem os teóricos que nomeia por "construtivistas". Os autores filiados a essa corrente dão ênfase a autoavaliação ou a avaliação interna, uma vez que o aluno estaria legitimado a realização da sua aprendizagem, o que dá uma margem muito grande de subjetividade à avaliação. Neste viés, as análises qualitativas têm predominância sobre as quantitativas, que não são consideradas propicias para perceber a realidade que cerca todo o processo educacional.

Como seria realizada a avaliação, desta maneira, sobre o prisma construtivista? Por meio da percepção das dificuldades apresentadas pelo 
aluno, que serviriam como um norte para a reformulação das práticas de ensino, permitindo que sempre que fosse percebida uma incoerência entre os objetivos e metas e a realidade, novas práticas e orientações fossem adotadas, garantindo-se o aprendizado. Neste prisma, o âmbito do contexto social em que está inserida a escola ou a universidade ganha ênfase, dado o fato de que é levado em consideração o habitus cultural que cada aluno acumulou ao longo de sua vida, para que seja possível diagnosticar as dificuldades que apresentam, percebendo a raiz dos seus erros.

As duas posições - positivistas e construtivistas - têm defeitos, na visão do autor. Isto porque reduziriam a questão da avaliação a um prisma maniqueísta, em que, de um lado, a avaliação seria classificatória, limitando-se a uma aferição de medida e, doutro, dispensaria todos os procedimentos para a identificação externa da aprendizagem pelo professor, deixando a avaliação a cargo exclusivamente do aluno. Por isso, uma posição dialética não poderia se render a uma análise embasada na mencionada dubiedade, dado o fato de que cada realidade concreta, cada ambiente educacional, em outras palavras, tem um contexto social que merece planejamento específico para a realização da avaliação do ensino e aprendizagem. Assim, a depender dos objetivos e metas institucionalmente adotados em ambientes de ensino, a avaliação teria função prognóstica, diagnóstica ou mesmo classificatória.

Dentro de um modelo de cunho liberal, uma avaliação que tenha por objetivo a medida da aprendizagem servirá como forma de selecionar quais indivíduos vão dar continuidade à progressão nos estudos, quais indivíduos ingressarão nas universidades e no mercado de trabalho, quais indivíduos ocuparão postos e cargos de trabalho mais ou menos relevantes, e assim sucessivamente. Isto porque ela faz parte do sistema, sendo assim concebida como uma ferramenta eficaz para o controle da hierarquia social em uma sociedade de classes.

Com isso, quer-se afirmar que se privilegia, em termos de avaliação do ensino e aprendizagem, uma determinada maneira de perceber a realidade ou, como explica Perrenoud (1999, p. 9), “[...] um modo de estar em aula e no mundo, valorizar formas e normas de excelência, definir um aluno modelo, aplicado e dócil para uns, imaginativo e autônomo para outros [...]". Assim é que se constata o fato de que avaliar, mais do que nunca, acaba significando estar e fazer parte de um contexto social e servir (ou não) aos seus objetivos. Trata-se, portanto, de uma ação política complexa que envolve o conhecimento que o sujeito que a realiza tem de si e do contexto em que se insere, sendo, por isso, muito difícil mudar muitas das ações pedagógicas que se desenvolvem dentro do ensino superior, que objetivam, basicamente, regular o trabalho e as relações dentro do ambiente social. Isto pode ser observado a partir do que Luckesi (2002) nomeia como "pedagogia do exame".

Cumprindo uma função domesticadora a avaliação serve para adequar os indivíduos ao sistema, e, por isso, o ensino superior acaba girando ao redor da classificação dos indivíduos, categorias em que eles serão enquadradados a partir da quantidade de conteúdo que conseguirem reproduzir com a máxima efetividade.

Assim, desde que os indivíduos consigam ter êxito em exames como esses, há não apenas conformidade, mas uma satisfação própria aos sistemas de ensino que passam a alardear a toda a sociedade a "qualidade" de suas práticas educativas, desconsiderando-se o que realmente vem a ser o ensino. Neste sentido,

Nos três graus de ensino, utilizam-se todo e qualquer teste ou tarefa realizada pelos estudantes com caráter de seleção à semelhança dos concursos, vestibulares e outros. $\mathrm{Na}$ escola, a avaliação não tem por finalidade a eliminação de candidatos tal como nos concursos classificatórios. Quando a finalidade é seletiva, o instrumento de avaliação é constatativo, prova irrevogável. Mas testes e tarefas, nas escolas devem se constituir em momentos de trocas de ideias entre professores e alunos na busca de um diálogo intelectual gradativo e sequencial (HOFFMANN, 2014, p. 67).

As instituições de ensino superior são locais de debates de ideias, de reflexões críticas, 
em que os indivíduos passam a entender seu contexto histórico-social para produzir conhecimento útil à transformação da sociedade. Neste quadro, a avaliação deve permitir o debate dessas ideias, e não servir de forma exclusiva como instrumento disciplinador de condutas sociais a serviço de um modelo liberal de sociedade, que produz indivíduos para competirem no mercado de trabalho entre si.

\section{NORMAS SOBRE A AVALIAÇÃO DA APRENDIZAGEM}

Nesta seção, analisa-se como a avaliação da aprendizagem é abordada pela legislação pátria a partir da Lei de Diretrizes e Bases da Educação Nacional (LDB - Lei no 9394/1996); da Lei no 10.861, de 14 de abril de 2004, que institui o Sistema Nacional de Avaliação do Ensino Superior (SINAES) e das Diretrizes Nacionais Curriculares (DCN) dos cursos de Direito, instituídas pela Resolução CNE/CES no 5, de 17 de dezembro de 2018.

\subsection{LEI DE DIRETRIZES E BASES DA EDUCAÇÃO NACIONAL}

A educação, de acordo com o artigo 10 da Lei de Diretrizes e Bases da Educação Nacional (LDB - Lei no 9394/1996) não se restringe aos espaços institucionais de promoção da educação - como escolas e universidades, por exemplo -, mas a toda a sociedade, a partir da vida em família e em sociedade de diversas maneiras distintas. Tanto que dentre os princípios que devem reger a educação nacional, a educação vem prevista como um dever do Estado e da família. Em relação a esses princípios, prevê o artigo 3ㅇ, inciso IX, a "garantia de padrão de qualidade".

Além disso, o artigo 4으, inciso $\mathrm{V}$ afirma que o Estado deverá garantir o acesso aos níveis mais elevados de ensino, a pesquisa e a criação artística a todos. $\mathrm{O}$ inciso IX do mesmo artigo afirma que ao Estado também deve garantir "padrões mínimos de qualidade de ensino, definidos como a variedade e quantidade mínimas, por aluno, de insumos indispensáveis ao desenvolvimento do processo de ensino e aprendizagem". No mesmo sentido, há previsão que os cursos superiores noturnos deverão manter os mesmos padrões de qualidade dos cursos diurnos (art. 48, §4ㅇ).

A iniciativa privada poderá desenvolver atividades no âmbito do ensino, cumprindo as normas gerais da educação nacional e dos sistemas de ensino, a partir da autorização do Poder Público e da verificação contínua de qualidade e, por fim, provando sua capacidade de autofinanciamento (art. 70, LDB).

$\mathrm{O}$ art. 9ㅇ, VI da LDB, prevê que é de competência da União "assegurar processo nacional de avaliação do rendimento escolar no ensino fundamental, médio e superior, em colaboração com os sistemas de ensino, objetivando a definição de prioridades e a melhoria da qualidade do ensino".

O sistema federal de ensino será composto das instituições mantidas pela União, pelos órgãos federais de educação (independentemente do nível) e das instituições privadas de ensino superior (art. 16, LDB). A União detém a competência para criar normas sobre os cursos de graduação e pós-graduação, bem como regular o sistema de avaliação do ensino superior.

Em relação ao processo de ensino e aprendizagem, de acordo com o art. 13 da LDB, além dos professores serem corresponsáveis pela elaboração do Projeto Pedagógico de Curso (PPC) da instituição ao qual estão vinculados, devem elaborar planos de trabalho coerentes com a proposta de suas instituições. Como o PPC deve observar o contexto econômico, social e cultural da região em que uma dada IES for implantada colaborando com a articulação entre ambiente educacional e comunidade -, a correlação com o plano de ensino se torna essencial ao trabalho docente. $O$ artigo 13 também prevê que os professores devem zelar pela aprendizagem dos discentes desenvolvendo estratégias para os alunos que não tiveram um bom desempenho melhorarem o mesmo.

Entre os artigos 43 a 67 a LDB regula a educação superior, estipulando as finalidades desse sistema, que abrangem não apenas a formação profissional para o mercado de trabalho, mas o desenvolvimento de uma visão crítica de mundo capaz de alterar a realidade social brasileira. É reconhecida a necessidade de suscitar no futuro profissional, independente da área, a capacidade de intervir em sua realidade, produzir conhecimento (através da pesquisa) e promover a sua difusão por meio da extensão.

Outro ponto importante da LDB diz respeito a formação dos professores para o ensino superior. De acordo com o artigo 66, "a preparação para o exercício do magistério superior far-se-á em nível de pós-graduação, prioritariamente em programas de mestrado e 
doutorado". Dando continuidade ao que prevê a LDB sobre a formação de professores, a resolução CNE/CES no 1, de 3 de abril de 2001 estabelece as normas para o funcionamento dos cursos de pósgraduação stricto sensu e lato sensu. Na primeira modalidade, que inclui os mestrados e doutorados, a resolução deixa muitas questões omissas, de modo que não estabelece parâmetros de como deve ocorrer a formação dos professores para o nível superior (VEIGA; D’ÁVILA, 2019).

Em relação ao planejamento das aulas e a avaliação do ensino e aprendizagem, há previsão na LDB (art. 57, V) de que as IES assegurem um período reservado para os estudos, planejamento das aulas e das avaliações, o que deve ser incluído na carga horária de trabalho.

\subsection{AVALIAÇÃO DO ENSINO E APRENDIZAGEM NO PPC DOS CURSOS}

A avaliação do ensino e aprendizagem é prevista na LDB, como se viu acima, no aspecto em que os docentes devem ter um período reservado aos estudos, planejamento das aulas e avaliações e a União deve assegurar a avaliação do rendimento escolar em todos os níveis de ensino. Neste sentido, a União tem fiscalizado a atuação das IES, em relação a avaliação do ensino e aprendizagem, a partir do Sistema Nacional de Avaliação do Ensino Superior (SINAES).

De acordo com a Lei no 10.861, de 14 de abril de 2004, que institui o SINAES, a avaliação institucional envolve a análise de alguns itens obrigatórios, tal como avaliação no âmbito do ensino e aprendizagem (art. 3으, VIII). As políticas institucionais sobre avaliação, assim, devem vir no projeto pedagógico do curso e no planejamento de desenvolvimento institucional. Existe, inclusive, indicador dentro dos instrumentos avaliativos de autorização que avalia a qualidade das políticas mencionadas. Veja-se:

Quadro 1. Procedimentos de acompanhamento e de avaliação dos processos de ensino e aprendizagem autorização de cursos

\section{CONCEITO \\ CRITÉRIO DE ANÁLISE}

1 Os procedimentos de acompanhamento e de avaliação, previstos para os processos de ensinoaprendizagem, não atendem à concepção do curso definida no PPC.

2 Os procedimentos de acompanhamento e de avaliação, previstos para o processo de ensinoaprendizagem, atendem à concepção do curso definida no PPC, mas não possibilitam o desenvolvimento e a autonomia do discente de forma contínua e efetiva ou não implicam informações sistematizadas e disponibilizadas aos discentes.

3 Os procedimentos de acompanhamento e de avaliação, previstos para o processo de ensinoaprendizagem, atendem à concepção do curso definida no PPC, possibilitando o desenvolvimento e a autonomia do discente de forma contínua e efetiva, e implicam informações sistematizadas e disponibilizadas aos estudantes.

4 Os procedimentos de acompanhamento e de avaliação, previstos para o processo de ensinoaprendizagem, atendem à concepção do curso definida no PPC, possibilitando o desenvolvimento e a autonomia do discente de forma contínua e efetiva, e implicam informações sistematizadas e disponibilizadas aos estudantes, com mecanismos que garantam sua natureza formativa.

5 Os procedimentos de acompanhamento e de avaliação, previstos para o processo de ensinoaprendizagem, atendem à concepção do curso definida no PPC, possibilitando o desenvolvimento e a autonomia do discente de forma contínua e efetiva, e implicam informações sistematizadas e disponibilizadas aos estudantes, com mecanismos que garantam sua natureza formativa, sendo planejadas ações concretas para a melhoria da aprendizagem em função das avaliações realizadas.

Fonte: BRASIL, 2017a.

Nota: Grifos no original.

No mesmo sentido o outro indicador do SINAES, referente ao reconhecimento e a renovação de reconhecimento de cursos (BRASIL, 2017b). Por isto, o MEC expediu a Portaria Normativa no 23, de 21 de dezembro de 2017 do MEC, que prevê que o PPC do curso deve ser 
disponibilizado de maneira pública para todos os alunos e interessados, para que verifiquem, dentre outras coisas, como ocorre o processo de ensino e aprendizagem em determinada IES:

Art. 99. A instituição
deverá afixar, em local
visível, junto à secretaria
acadêmica, as condições
de oferta do curso,
informando,
especificamente:
Omissis § 1o A instituição
manterá, em página
eletrônica própria e
também na secretaria
acadêmica, para consulta
dos alunos ou
interessados, o registro
oficial devidamente
atualizado das
informações referidas no
caput, além dos seguintes
elementos: I - íntegra do
PPC, com componentes
curriculares, sua duração,
requisitos e critérios de
avaliação; II - conjunto de
normas que regem a vida
acadêmica, incluídos o
estatuto ou regimento
(BRASIL, 2017).

Como se percebe, embora a previsão da avaliação ainda seja resumida, existem alguns parâmetros que reforçam que ela deve ter, no mínimo, um perfil formativo, correspondendo a visão planejada para o curso e permitindo a autonomia discente. O retorno ou feedback da avaliação é previsto nos instrumentos avaliativos, garantindo-se, ao discente, informações públicas e sistematizadas sobre as avaliações. Percebe-se, também, que o planejamento para o ensino superior, de acordo com a Diretoria de Avaliação da Educação Superior (DAES) deve utilizar o resultado dessas avaliações para aprimorar o processo de ensino continuamente.

Reconhece-se a autonomia das IES para formularem suas próprias políticas avaliativas, que devem vir inseridas no PPC, para que toda a sociedade, e não apenas os discentes do curso ou futuros discentes possam acompanhar essas políticas, assim como o Estado, em sua função regulatória. Desse modo, não se trata de uma opção da IES manter ou não a sociedade informada de seu planejamento, ela tem a obrigação de publicizar tais informações, pois elas funcionam como pactos negociados entre IES e comunidade acadêmica, em que os planos, objetivos e metas devem estar bem delineados.

\subsection{AVALIAÇÃO DA APRENDIZAGEM NAS DCN DOS CURSOS DE DIREITO}

Aos cursos de Direito são aplicadas as Diretrizes Nacionais Curriculares (DCN) do curso, que contém a forma de organização do mesmo, a estrutura dos currículos, formas de avaliação etc.

Ao final de 2018 ocorreu uma mudança significativa nas DCN dos cursos de Direito, com a publicação da Resolução CNE/CES no 5, de 17 de dezembro de 2018. Nela foram instituídas novas diretrizes gerais para os cursos de Direito, revogando-se a resolução vigente, até então (Resolução CNE/CES no 9/2004). Os principais pontos das novas diretrizes são analisados a seguir.

No PPC do curso devem vir algumas informações essenciais, como o perfil do graduando; competências, habilidades e conteúdos curriculares básicos, voltados ao desenvolvimento profissional; a prática jurídica; atividades complementares; o sistema de avaliação do ensino e aprendizagem; a forma que será organizado o Trabalho de Curso (TC); a forma de oferta do regime acadêmico e a duração do curso (art. 2으, incisos I a VIII).

Um dos pontos mais importantes dessa reforma, em relação a avaliação do ensino e aprendizagem, foi a necessária inserção, desde o PPC, das maneiras como ela deve ocorrer, definida de maneira geral no planejamento do curso. Mas, mesmo a avaliação do ensino e aprendizagem tendo sido mencionada nesse ponto, nota-se que foi prevista de forma genérica. Ou seja, a DCN prevê apenas que a avaliação deve estar prevista no PPC do curso. A resolução centraliza suas atenções na avaliação da extensão e nas avaliações externas, entre os artigos 10 a 12 do mencionado dispositivo, desprivilegiando a avaliação da aprendizagem.

Desta forma, a avaliação da aprendizagem, bem como as demais competências pedagógicas necessárias ao ensino, ficam restritas, muitas vezes, ao PPC de cada curso. Mesmo os programas de mestrado e doutorado, como prevê o artigo 66 da LDB, têm se omitido em ofertar disciplinas voltadas a atuação em sala de aula, como será visto a seguir.

4 A FORMAÇÃO DO PROFESSOR DOS CURSOS 


\section{SUPERIORES DE DIREITO NOS MESTRADOS E DOUTORADOS NO NORDESTE}

A Comissão de Aperfeiçoamento de Pessoal do Nível Superior (CAPES), órgão que avalia os cursos de pós-graduação no Brasil, disponibiliza relatórios quantitativos e qualitativos sobre as avaliações dos cursos de pós-graduação em Direito a cada dois anos.
Nestes relatórios, é possível verificar não apenas a nota das instituições de pós-graduação em Direito, mas o perfil do corpo docente, suas produções, linhas de pesquisa, etc. Em 2018, existiam no país 99 cursos de mestrado acadêmico e 36 cursos de doutorado oficialmente reconhecidos pela CAPES:

Quadro 2. Total de programas e cursos de pós-graduação stricto sensu em Direito no Brasil

\begin{tabular}{|l|l|l|l|l|l|l|l|l|l|l|l|l|l|}
\hline & \multicolumn{4}{|l|}{ Total de programas de pós-graduação } & \multicolumn{4}{c|}{ Totais de cursos de pós-graduação } \\
\hline & Total & ME & DO & MP & DP & ME/DO & MP/DP & Total & ME & DO & MP & DP \\
\hline & 130 & 57 & 1 & 20 & 0 & 52 & 0 & 182 & 109 & 53 & 20 & 0 \\
\hline Totais & 130 & 57 & 1 & 20 & 0 & 52 & 0 & 182 & 109 & 53 & 20 & 0 \\
\hline
\end{tabular}

Legendas:

ME: Mestrado Acadêmico

DO: Doutorado Acadêmico

MP: Mestrado Profissional

DP: Doutorado Profissional

ME/DO: Mestrado Acadêmico e Doutorado Acadêmico

MP/DP: Mestrado Profissional e Doutorado Profissional.

Fonte: CAPES, 2020.

Nota: Dados trabalhados pelas autoras.

Os dados fornecem um panorama geral dos cursos de pós-graduação em Direito no Brasil. Como seria inviável avaliar todos eles, foi realizado um recorte para análise do contexto do Nordeste, foi possível identificar 24 cursos de pós-graduação stricto sensu em 16 IES funcionando na região: 16 mestrados acadêmicos, 7 doutorados e 1 mestrado profissional em Direito na região. Além disso, a
CAPES também disponibilizou informações dos projetos em andamento para abertura de 5 novos cursos de pós-graduação stricto sensu em Direito: 4 mestrados acadêmicos e 1 mestrado profissional, o que pode ser aferido dos dados da CAPES publicados em 2020, como é possível identificar a seguir:

Quadro 3. Total de cursos de pós-graduação stricto sensu em direito no Nordeste e as notas dos programas em 2020

\begin{tabular}{|c|c|c|c|c|c|c|}
\hline UF & IES & Nome do Programa & ME & DO & MP & DP \\
\hline \multirow[t]{2}{*}{ AL } & Centro Universitário Cesmac (CESMAC) & Direito & A & - & - & - \\
\hline & Universidade Federal de Alagoas (UFAL) & Direito & 3 & - & - & - \\
\hline \multirow[t]{3}{*}{ BA } & Universidade Federal da Bahia (UFBA) & Direito & 5 & 5 & - & - \\
\hline & Universidade Católica de Salvador (UCSAL) & Direito & $A$ & - & - & - \\
\hline & Centro Universitário FG (UNIFG) & Direito & 3 & - & - & - \\
\hline \multirow[t]{5}{*}{ CE } & Universidade Federal do Ceará (UFC) & Direito & 4 & 4 & - & - \\
\hline & Centro Universitário Christus (UNICHRISTUS) & Direito & 3 & - & - & - \\
\hline & Centro Universitário 7 de Setembro (UNI7) & Direito & 3 & - & - & - \\
\hline & Universidade de Fortaleza (UNIFOR) & $\begin{array}{l}\text { Direito } \\
\text { Constitucional }\end{array}$ & 6 & 6 & - & - \\
\hline & Universidade de Fortaleza (UNIFOR) & $\begin{array}{l}\text { Direito e Gestão de } \\
\text { Conflitos }\end{array}$ & - & - & 3 & - \\
\hline \multirow[t]{2}{*}{ MA } & Universidade Ceuma (UNICEUMA) & $\begin{array}{l}\text { Direito e Afirmação } \\
\text { de Vulneráveis }\end{array}$ & - & - & A & - \\
\hline & Universidade Federal do Maranhão (UFMA) & Direito e Instituições & 3 & - & - & - \\
\hline
\end{tabular}




\begin{tabular}{|c|c|c|c|c|c|c|}
\hline & & $\begin{array}{l}\text { do Sistema de } \\
\text { Justiça }\end{array}$ & & & & \\
\hline \multirow[t]{2}{*}{ PB } & $\begin{array}{l}\text { Universidade Federal da Paraíba, João Pessoa } \\
\text { (UFPB-JP) }\end{array}$ & Ciências Jurídicas & 4 & 4 & - & - \\
\hline & Centro Universitário de João Pessoa (UNIPÊ) & Direito & 3 & - & - & - \\
\hline \multirow[t]{3}{*}{ PE } & $\begin{array}{l}\text { Universidade Católica de Pernambuco } \\
\text { (UNICAP) }\end{array}$ & Direito & 4 & 4 & - & - \\
\hline & Universidade Federal de Pernambuco (UFPE) & Direito & 4 & 4 & - & - \\
\hline & Faculdade Damas da Instrução Cristã (FADIC) & Direito & 3 & - & - & - \\
\hline PI & $\begin{array}{l}\text { Fundação Universidade Federal do Piauí } \\
\text { (FUFPI) }\end{array}$ & Direito & A & - & - & - \\
\hline \multirow[t]{2}{*}{ RN } & $\begin{array}{l}\text { Universidade Federal Rural do Semi-Árido } \\
\text { (UFERSA) }\end{array}$ & Direito & A & - & - & - \\
\hline & $\begin{array}{l}\text { Universidade Federal do Rio Grande do Norte } \\
\text { (UFRN) }\end{array}$ & Direito & 3 & - & - & - \\
\hline \multirow[t]{2}{*}{ SE } & $\begin{array}{l}\text { Fundação Universidade Federal de Sergipe } \\
\text { (FUFSE) }\end{array}$ & Direito & 3 & - & - & - \\
\hline & Universidade Tiradentes (UNIT-SE) & Direitos Humanos & 4 & 4 & - & - \\
\hline \multicolumn{3}{|c|}{ Total de cursos (excetuando-se os que ainda não estão em funcionamento) } & 16 & 7 & 1 & 0 \\
\hline
\end{tabular}

Legendas:

ME: Mestrado Acadêmico

DO: Doutorado Acadêmico

MP: Mestrado Profissional

DP: Doutorado Profissional

A: Curso em projeto

Fonte: CAPES, 2020b

Nota: Dados trabalhados pelas autoras.

Para identificar, de maneira qualitativa, o problema da ausência do aporte pedagógico nos cursos em funcionamento, foram analisados, a partir dos dados disponibilizados pela CAPES e pelas próprias IES, o currículo dos professores dos cursos, por meio da Plataforma Lattes. O seguinte conjunto de critérios serviu de base para o processo de busca: a) quantidade total de docentes dos cursos de mestrado acadêmico, mestrado profissional, doutorado acadêmico e doutorado profissional (excetuando-se professores visitantes e colaboradores); b) docentes com algum tipo de pós-graduação stricto sensu que lecionem disciplinas relacionadas à formação docente nos cursos; $c)$ linhas de pesquisa e/ou extensão sobre o ensino jurídico; d) disciplinas que auxiliem no processo de formação para o ensino jurídico. Não foram considerados os projetos de mestrado em curso, apenas os que já estão em funcionamento. $O$ resultado pode ser conferido no quadro que se segue:

Quadro 4. Disciplinas voltadas à preparação para o ensino jurídico em cursos de pós-graduação stricto senso em Direito no Nordeste

\begin{tabular}{|c|c|c|c|c|c|c|c|c|}
\hline \multirow[t]{2}{*}{ Sigla das IES } & \multirow[t]{2}{*}{ UF } & \multicolumn{4}{|c|}{ Curso } & \multirow[t]{2}{*}{ Nome da disciplina } & \multirow[t]{2}{*}{ Carga Horária } & \multirow[t]{2}{*}{ Caráter } \\
\hline & & $\mathrm{M}$ & MP & D & DP & & & \\
\hline \multirow[t]{2}{*}{ UFAL } & $\mathrm{AL}$ & 3 & - & - & - & $\begin{array}{l}\text { Metodologia da Pesquisa } \\
\text { Sociojurídica: epistemologia, } \\
\text { métodos e didática no ensino } \\
\text { jurídico }\end{array}$ & $45 \mathrm{~h}$ & Obrigatória \\
\hline & & & & & & Estágio docência & $45 \mathrm{~h}$ & Obrigatória \\
\hline UFBA & BA & 5 & - & 5 & - & Tirocínio Docente Orientado & $68 \mathrm{~h}$ & Obrigatória \\
\hline UNIFG & $\mathrm{BA}$ & 3 & - & - & - & $\begin{array}{l}\text { Metodologia do Ensino e da } \\
\text { Pesquisa }\end{array}$ & $30 \mathrm{~h}$ & $S / I$ \\
\hline
\end{tabular}




\begin{tabular}{|c|c|c|c|c|c|c|c|c|}
\hline & & & & & & Seminário de Docência & $30 \mathrm{~h}$ & Obrigatória \\
\hline \multirow[t]{2}{*}{ UFC } & \multirow[t]{2}{*}{ CE } & \multirow[t]{2}{*}{4} & \multirow[t]{2}{*}{-} & \multirow[t]{2}{*}{4} & \multirow[t]{2}{*}{-} & Metodologia do Ensino Jurídico & $32 \mathrm{~h}$ & Optativa \\
\hline & & & & & & Estágio docência I & $32 \mathrm{~h}$ & Obrigatória \\
\hline UNICHRISTUS & $\mathrm{CE}$ & 3 & - & - & - & $\begin{array}{l}\text { Metodologia da educação } \\
\text { jurídica, avaliação e } \\
\text { desenvolvimento }\end{array}$ & $45 \mathrm{~h}$ & Optativa \\
\hline UNI7 & CE & 3 & - & - & - & $\begin{array}{l}\text { Metodologia do ensino e da } \\
\text { pesquisa jurídica }\end{array}$ & $S / I$ & Obrigatória \\
\hline \multirow[t]{2}{*}{ UNIFOR } & \multirow[t]{2}{*}{ CE } & \multirow[t]{2}{*}{6} & \multirow[t]{2}{*}{-} & \multirow[t]{2}{*}{6} & \multirow[t]{2}{*}{-} & Didática do ensino jurídico & $45 \mathrm{~h}$ & Obrigatória \\
\hline & & & & & & Estágio docência & $45 \mathrm{~h}$ & Optativo \\
\hline UNIFOR & CE & - & 3 & - & - & $S / I$ & $S / I$ & $S / I$ \\
\hline UFMA & MA & 3 & - & - & - & Tirocínio Jurídico & $60 \mathrm{~h}$ & Optativa \\
\hline UFPB-JP & PB & 4 & - & 4 & - & Estágio Docência & $60 \mathrm{~h}$ & Optativa \\
\hline UNIPÊ & PB & 3 & - & - & - & $\mathrm{S} / \mathrm{I}$ & $S / I$ & $S / I$ \\
\hline UNICAP & $\mathrm{PE}$ & 4 & - & 4 & - & Estágio Docência & $2 / 4$ créditos* & Optativa \\
\hline UFPE & $\mathrm{PE}$ & 4 & - & 4 & - & Estágio docência & $30 \mathrm{~h}$ & Optativa \\
\hline FADIC & $\mathrm{PE}$ & 3 & - & - & - & $S / I$ & $S / I$ & $S / I$ \\
\hline UFRN & RN & 3 & - & - & - & Estágio docência & $60 \mathrm{~h}$ & Optativa \\
\hline \multirow[t]{2}{*}{ FUFSE } & \multirow[t]{2}{*}{ SE } & \multirow[t]{2}{*}{3} & \multirow[t]{2}{*}{-} & \multirow[t]{2}{*}{-} & \multirow[t]{2}{*}{-} & $\begin{array}{l}\text { Metodologia do ensino e } \\
\text { pesquisa em direito }\end{array}$ & $60 \mathrm{~h}$ & Obrigatória \\
\hline & & & & & & Estágio docência & $90 \mathrm{~h}$ & Obrigatória \\
\hline UNIT-SE & SE & 4 & - & 4 & - & Estágio docência & $\begin{array}{l}\text { Até } 6 \mathrm{~h} \text { por } \\
\text { semana } \\
\text { durante } 1 \\
\text { semestre }\end{array}$ & Obrigatória \\
\hline
\end{tabular}

Legendas:

S/I: Não foram disponibilizadas informações oficiais sobre a informação.

* 2 créditos para o mestrado e 4 para o doutorado.

Fonte: UFAL, UFBA, UNIFG, UFC, UNICHRISTUS, UNI7, UNIFOR, UFMA, UFPB-JP, UNIPÊ, UNICAP, UFPE, FADIC, UFRN, FUFSE, UNIT-SE, 2020

Nota: Dados trabalhados pelas autoras.

As 16 IES analisadas representam 24 programas de mestrado acadêmico, mestrado profissional e doutorado acadêmico no Nordeste, como é possível identificar no quadro acima. Dessas IES, 7 apresentam disciplinas voltadas à preparação para o magistério jurídico. A nomenclatura dessas disciplinas varia bastante: metodologia da pesquisa sociojurídica: epistemologia, métodos e didática no ensino jurídico; metodologia do ensino e da pesquisa; metodologia do ensino jurídico; metodologia da educação jurídica, avaliação e desenvolvimento e didática do ensino jurídico.

A análise das ementas revela algumas informações importantes. Das sete disciplinas com enfoque pedagógico, 4 também tinham como objetivo desenvolver competências e habilidades para pesquisa. Ou seja, em disciplinas que variam de $30 \mathrm{~h}$ à $60 \mathrm{~h}$ por semestre, mais da metade tem sua carga horária dividida com conteúdos relacionados à pesquisa. Pode-se refletir disto que a parte do currículo voltada à preparação para a sala de aula é ínfima, pois já seria pouco incluir toda a formação didáticopedagógica do docente em uma única disciplina de $30 \mathrm{~h}, 45 \mathrm{~h}$ ou $60 \mathrm{~h}$. Além disso, das 7 disciplinas analisadas, apenas 3 mencionam a avaliação da aprendizagem em suas ementas.

O quadro acima revela, também, que 12 das IES analisadas apresentam disciplinas para o estágio docência. Deve-se lembrar que, de acordo com o regulamento da CAPES para concessão de bolsas de mestrado ou doutorado, o estágio docência é obrigatório a todos os bolsistas. Isto significa que, no quadro acima, as disciplinas relacionadas ao estágio como optativas se referem aos alunos que não são bolsistas. Neste sentido, como explica Prado (2015), a presença de tal disciplina no currículo jurídico não se traduz na preocupação do corpo 
docente com a preparação pedagógica dos futuros professores de Direito, mas em requisito que se faz obrigatório pela Capes para os bolsistas de mestrado e doutorado.

Quadro 5. Relação entre a formação dos professores dos cursos de pós-graduação stricto senso e as disciplinas relacionadas ao ensino jurídico

\begin{tabular}{|c|c|c|c|c|c|}
\hline $\begin{array}{l}\text { Quantidade de } \\
\text { IES que } \\
\text { oferecem } \\
\text { Pós-Graduação } \\
\text { stricto senso } \\
\text { em Direito no } \\
\text { Nordeste }\end{array}$ & $\begin{array}{l}\text { Quantidade de } \\
\text { cursos Pós- } \\
\text { Graduação } \\
\text { stricto senso em } \\
\text { Direito no } \\
\text { Nordeste }\end{array}$ & $\begin{array}{l}\text { Docentes com Pós- } \\
\text { Graduação stricto } \\
\text { sensu em educação } \\
\text { que lecionem } \\
\text { disciplinas } \\
\text { relacionadas à } \\
\text { formação docente }\end{array}$ & $\begin{array}{l}\text { Linha de } \\
\text { Pesquisa, } \\
\text { projeto de } \\
\text { pesquisa ou de } \\
\text { extensão sobre } \\
\text { a educação } \\
\text { jurídica }\end{array}$ & $\begin{array}{l}\text { Disciplina } \\
\text { voltada à } \\
\text { preparação } \\
\text { para o ensino } \\
\text { jurídico }\end{array}$ & $\begin{array}{c}\text { Disciplina } \\
\text { Estágio } \\
\text { Docência }\end{array}$ \\
\hline 16 & 24 & 1 & 1 & 7 & 12 \\
\hline
\end{tabular}

Fontes: UFAL, UFBA, UNIFG, UFC, UNICHRISTUS, UNI7, UNIFOR, UFMA, UFPB-JP, UNIPÊ, UNICAP, UFPE, FADIC, UFRN, FUFSE, UNIT-SE, 2020,

Nota: Dados trabalhados pelas autoras.

Esse quadro revela algumas informações: primeiro, que grande parte dos docentes que lecionam nas disciplinas relacionadas à formação para o magistério jurídico não tiveram uma educação formal em práticas pedagógicas. Como implicação prática, continuam a se reproduzir modelos tradicionais de ensino e avaliação na formação dos mestres e doutores em Direito. Prado (2015, p. 415) expressa neste sentido:

$$
\begin{aligned}
& \text { Grande parte dos atuais } \\
& \text { professores dos } \\
& \text { bacharelados em Direito, } \\
& \text { por não apresentarem } \\
& \text { formação específica para o } \\
& \text { magistério no ensino } \\
& \text { superior, limitam-se à } \\
& \text { reprodução do modelo } \\
& \text { positivista de ensino no } \\
& \text { qual foram formados em } \\
& \text { suas graduações, } \\
& \text { desconsiderando os } \\
& \text { conhecimentos } \\
& \text { pedagógicos } \\
& \text { indispensáveis à docência. }
\end{aligned}
$$

Outro dado relevante é a ausência de linhas de Pesquisa, projetos de pesquisa ou de extensão sobre a formação docente, o que pode ser traduzido como a falta de preocupação com a atuação dos juristas em sala de aula e com a melhoria da atuação do professor. Mais uma vez, neste sentido, traz-se a reflexão de Prado (2015, p. 452), que expressa bem a realidade nesses cursos:

\begin{abstract}
$\mathrm{Na}$ realidade, os muitos que ministram aula nos cursos de Direito não são professores, são juízes, promotores, advogados e demais operadores do Direito que, como complemento de renda ou, como alguns dizem, "por vocação", assumem aulas nos cursos de bacharelado. O critério de escolha para a docência limita-se, por vezes, à atuação profissional e, numa transposição acrítica, acredita-se que, se a pessoa é um bom juiz, um bom advogado, necessariamente, será um bom professor.
\end{abstract}

Por fim, é alarmante que do total de programas analisados, apenas 7 tenham disciplinas específicas para a atuação no magistério, e que, mesmo assim, a carga horária e os conteúdos incluídos na disciplina sejam bastante restritos. Como pôde ser visto, apenas 3 dessas disciplinas têm a avaliação em suas ementas. Por isso, não se pode dizer que oferecem uma base adequada para atuação em sala de aula, pois algumas mesclam metodologia do ensino com metodologia da pesquisa, em cargas horárias reduzidas. No mesmo sentido, a pesquisa de Prado realizada em 2015, cujos dados reforçam a análise ora esboçada, 
revelando a grande deficiência na formação do professor para a sala de aula.

\subsection{RESSIGNIFICAR O ENSINO JURÍDICO PARA AVALIAR DE FORMA DIALÉTICA}

O que se percebe, dos dados analisados, é que há uma grande carência na formação dos professores que atuarão lecionando em cursos de Direito, pelo menos em relação aos que optaram por fazer mestrado e/ou doutorado na própria área jurídica. Torna-se urgente, desta maneira, que os professores que lecionem nesta esfera percebam a grave falha nos currículos dos programas de pós-graduação stricto sensu e busquem maneiras de ressignificar seu papel em sala de aula.

Ainda prevalecem, em cursos jurídicos, práticas tradicionais que verticalizam a sala de aula, em que o professor assume o protagonismo do processo educativo. Neste sentido,

[...] em função da necessidade de alimentar a máquina burocrática estatal, o início do ensino jurídico no país foi marcado pela absoluta ausência da preocupação da formação pedagógica dos professores, vez que para atender a finalidade a qual os cursos se prestavam bastavam aulas meramente expositivas, em que os professores despejavam 0 conhecimento nas salas de aula e os alunos deveriam absorvê-los o máximo possível. Transcorridos mais de 150 anos dos primeiros cursos de Direito no país, os atuais cursos jurídicos ainda possuem muitas semelhanças com aquele modelo introduzido no século XIX, vide a forte presença do dogmáticojurídico pautado num ensino conteudista e unidisciplinar. Dessa forma, observa-se que muito desse atraso na educação jurídica é devido a tradicional ausência de preocupação com a formação docente. Ainda vigora no mundo acadêmico do Direito, o pensamento falacioso de que para a docência basta o domínio do conhecimento específico em determinada área (ABIKAIR NETO, 2014, p. 34).

Além dos estudos já mencionados, como o de Abikair Neto (2014) e Prado (2015), outros autores também têm estudado a qualidade do ensino nos cursos jurídicos (RODRIGUES, 1993; ADEODATO, 1999; CASTRO, 2004; MORAIS, SANTOS 2007; MACHADO, 2009; MURARO, 2010; GONÇALVES; SANTOS, 2013; PALMEIRA, 2018; CORDEIRO, 2019).

São muitas as questões que têm despertado esse debate: a proliferação desenfreada de tais cursos, no âmbito privado; a precariedade com as quais têm se desenvolvido as práticas de ensino e aprendizagem; as relações tradicionais entre professores e alunos, em um claro sistema de verticalidade nas práticas educativas, dentre tantas outras.

A avaliação da aprendizagem, dentro do ensino do Direito, precisa ser analisada a partir da conjuntura na qual o curso se insere, uma vez que esses cursos são responsáveis por formar muitos dos agentes do Estado no âmbito de seu aparelho burocrático. Como o ensino nunca é neutro, mas, ao contrário, está a serviço das ideologias dominantes, o ensino servirá antes de tudo, à ideologia liberal e aos interesses de mercado, o que gera diversas implicações para a esfera pedagógica.

Primeiramente, isso irá resultar na construção de uma matriz curricular que atenda às necessidades mais urgentes do Estado e do mercado, optando-se pela escolha de disciplinas que revelem sua utilidade na prática e que reflitam as mudanças sociais e tecnológicas de uma sociedade globalizada e em plena expansão (RODRIGUES, 1993; ADEODATO, 1999).

Em segundo lugar, a forma como o ensino será realizado vai corresponder ao tipo de profissional que se deseja, que é aquele que domina todo o aparato normativo que sustenta a ordem normativa nacional e internacional. Assim, esse ensino será percebido na pobreza da formação pedagógica dos professores, que, buscando dominar esse ordenamento para sua atuação profissional, irão cobrar exatamente o 
mesmo dos seus alunos, o que se revela em aulas majoritariamente expositivas e sem real diálogo entre docentes e discentes (BASTOS, 2000; AGUIAR, 2004).

Como reflexo dessa ausência de preparação, à avaliação será relegado o papel de medir conhecimentos, a preparação técnica ou a desenvoltura de estudantes para a atuação profissional. Será utilizada quase sempre como um teste, confundindo-se mesmo o seu real significado com o dele (BASTOS, 2000). Perde-se por completo o sentido do ensino, na medida em que ele passa a servir a formatação dos indivíduos para a atuação no âmbito profissional, quando, em verdade, esse é apenas um dos aspectos da formação que deveria ocorrer em nível superior (MURARO, 2010).

Torna-se urgente, deste modo, no atual contexto em que se encontram os cursos de Direito, superar grandes dicotomias que ainda permeiam o estudo da avaliação do ensino e aprendizagem, como a utilização do viés positivista. É preciso compreender que toda avaliação deve ser processual, deve estar envolta no processo de ensino e aprendizagem, uma vez que faz parte desse processo de maneira inseparável.

A cultura que ainda prevalece, no ensino superior como um todo, é o da aferição de conhecimentos por meio de notas, pura e simplesmente, no que Luckesi (2002) chama de verificação da aprendizagem. Essa visão da avaliação precisa ser superada, pois produz uma profunda anomia no âmbito educativo que é transposta para o ambiente social, sendo reproduzida na iniciativa privada, no poder público e entre os indivíduos. Doutro lado, a práxis educativa também é transposta pelas ideologias dominantes em um dado contexto social. Em verdade, escolas e universidades acabam se tornando aparelhos ideológicos do Estado, moldando os indivíduos com sanções, exclusões, seleções, hierarquizações etc., (ALTHUSSER, 1985) como é o caso do modelo tradicional de avaliação que se realiza em grande parte desses ambientes.

\subsubsection{Alguns caminhos possíveis}

A avaliação do ensino e aprendizagem precisa ser integrada, de fato, à atividade de ensino como componente indissociável do processo de aprendizagem, sendo utilizada para melhorar a forma como docentes e discentes constroem o conhecimento em sala de aula. Não pode se resumir à aplicação de testes e exames, dada à evolução do estudo desta grande ciência e a quantidade de pesquisas na área.

Os programas de pós-graduação, que deveriam preparar os docentes para o ensino, pesquisa e extensão, dificilmente oferecem formação voltada para a atuação no tripé universitário, focando, principalmente, na especialização do conhecimento por área. Em seus programas, poucas disciplinas são oferecidas no campo da didática, avaliação e pedagogia do ensino superior. Conforme Sônego (2015, p. 31), até mesmo as licenciaturas têm pecado quanto à preparação para a sala de aula, uma vez que a maioria dedica pouca atenção ao processo de ensino e aprendizagem. Em suas palavras:

Na falta de uma formação
docente adequada, o
professor universitário
aporta-se em modelos
docentes observados por
ele enquanto aluno. Esse
modelo de formação é
fruto de uma educação
característica das
sociedades industriais, no
qual a crença na inovação
tecnológica e na sua
capacidade de reproduzir
essa lógica traz ao
indivíduo os méritos de ser
um profissional que deve
repassar seus
conhecimentos.

É preciso superar a lógica utilitarista que os diversos governos que passaram pelo país tentaram imprimir no ensino superior brasileiro. A formação nesse nível não pode ser rebaixada a uma simples formação para o mercado de trabalho, ou seja, uma formação exclusivamente técnica e profissional. É neste sentido que se têm produzido políticas públicas diversas no ensino superior, partindo da lógica que só um conhecimento útil ao desenvolvimento econômico deve receber investimentos, o que não seria o caso, por exemplo, das ciências sociais e humanas, sistematicamente deixadas de lado em matéria de desenvolvimento de pesquisas (SÔNEGO, 2015).

Neste sentido, as decisões do atual governo precarizam de forma sistemática o ensino superior. Pode-se citar, por exemplo, o corte de gastos para as bolsas de pós-graduação, em especial na área de humanas, uma vez que 
essa seria uma área com menor potencial para a produção de novos conhecimentos úteis ao setor empresarial do país (REVISTA FÓRUM, 2019).

Para que a avaliação da aprendizagem deixe de ser enxergada de maneira tradicional pelos docentes, é necessária uma preparação para o magistério propriamente dita, o que envolve a inclusão de disciplinas relacionadas com a pedagogia ou andragogia a formação docente que ocorre nos programas de pósgraduação stricto sensu em Direito.

Como pôde ser visto, embora exista previsão na LDB para que a docência do ensino superior seja exercida preferencialmente por professores com mestrado e/ou doutorado, a legislação sobre o assunto deixa muitas questões sem regulamentação legal.

Sobre o assunto, comentam Veiga e d'Ávila (2019, s.n):

[...] Por outro lado, a IES não pode se eximir de sua responsabilidade de oferecer oportunidades para que uma formação contínua se instale, e, dessa forma, os docentes possam se sentir mais seguros no desenvolvimento de seu ofício. Mas nem 0 contexto legal auxilia muito na constituição de bases para essa formação. Se fizermos uma análise da evolução (involução?) da legislação sobre o assunto, perceberemos que, no Brasil, de fato não há ainda uma política explícita de formação docente para esse nível de educação.

Como explicam as autoras, com o tempo a preocupação com esses cursos tem diminuído no âmbito da legislação, como é o caso da resolução CNE/CES no 1, de 3 de abril de 2001, que disciplina as regras gerais para 0 funcionamento dos cursos de pós-graduação lato sensu e stricto sensu no Brasil. Na mencionada resolução, omitiu-se a carga horária mínima para os cursos de mestrado e doutorado, além de ignorar a necessidade de formação pedagógica que os professores desses cursos precisariam ter para atuar na docência (VEIGA; D'ÁVILA, 2019). A preparação do professor para atuar no magistério superior, desse modo, se torna uma questão emblemática no país, na medida em que a legislação deixa muitos questionamentos em aberto de como essa formação pode acontecer.

Já Pimenta, Anastasiou e Cavallet (2003, p. 269) apontam que "[...] o aperfeiçoamento da docência universitária exige, pois, uma integração de saberes complementares. Diante dos novos desafios para a docência, o domínio restrito de uma área científica do conhecimento não é suficiente".

Por isso, é preciso repensar todo o magistério desse nível para incluir na formação dos futuros professores de Direito disciplinas que os ajudem, de fato, a compreender os vários liames que envolvem o processo de ensino e aprendizagem, como a avaliação.

Disciplinas necessárias à formação docente precisam ser inseridas no programa dos cursos de pós-graduação stricto senso em Direito, pois estes são principais cursos, ainda hoje, que mais formam professores para atuarem no magistério jurídico. A formação para a sala de aula precisa estimular uma postura dialética do professor, para que este compreenda as necessidades de seus alunos, dando a eles autonomia e liberdade para que desenvolvam suas potencialidades.

Como explicam Castanho e Freitas (2006, p. 96):

O papel do professor no contexto do ensino superior remete a uma postura ativa, dialética, política e ética, fazendo com que este educador tenha um compromisso permanente com a vida dos alunos, assim como com a autonomia de seus educandos, oportunizando espaços onde a liberdade possa ser exercida de forma criativa e espontânea.

Diante do esboçado, resta uma questão: quais disciplinas deveriam fazer parte dos currículos das pós-graduações em Direito, a fim de possibilitar a construção de uma base sólida para atuação nos cursos jurídicos, superando-se a metodologia tradicional que ainda prevalece nos mesmos?

Algumas disciplinas deveriam ser incluídas nos cursos de pós-graduação stricto 
sensu em Direito, pois toda metodologia de ensino passa pelo uso de métodos e técnicas auxiliares à atuação do professor. Para que este possa fazer uso de qualquer metodologia em sala de aula é necessário, antes, conhecer quais métodos existem e suas finalidades (BARBEL, 1995).

A primeira das ciências que se fazem necessárias nesse caminho da formação do docente do ensino superior é a pedagogia, que não se restringe a educação de crianças e jovens, mas que também se refere a educação de adultos, pois pode ser conceituada como "o estudo sistemático da educação" (HAYDT, 2006, p. 15). Como explica Cunha (2004), em um dos seus estudos sobre o ensino superior, toda prática pedagógica está ligada a formação de professores, sendo a docência (em qualquer nível de ensino) uma prática que deve ser construída permanentemente. Sobre o docente do ensino superior, a autora pontua que o trabalho pedagógico acaba assumindo a periferia da construção dos cursos superiores, sendo desprivilegiado ao se restringir a construção (quando muito) dos planejamentos curriculares, projetos pedagógicos e na construção do planejamento da avaliação do ensino e aprendizagem.

Além da pedagogia, a didática aparece como uma disciplina essencial ao desenvolvimento de saberes relacionados ao ensino. Envolve o estudo do ensinar e aprender, duas ações inseparáveis na ação docente. Conforme Libâneo (2015, p. 633):

[...] a didática é assumida como uma disciplina pedagógica indispensável ao exercício profissional, constituindo-se referência para a formação de professores à medida que investiga os marcos teóricos e conceituais que fundamentam, a partir das práticas reais de ensinoaprendizagem, os saberes profissionais a serem mobilizados na ação docente, de modo a articular na formação profissional a teoria e a prática.

A didática se torna essencial a formação do professor para o magistério do ensino superior, porque ela permite que a construção do conhecimento aconteça por meio de uma ação conjunta entre professores e alunos. Veiga (2000, p. 175) compreende a didática como um "lócus produtivo da aprendizagem", pois todo o ensino deve gerar algo novo, como uma postura questionadora da realidade, capaz de transformar o ambiente social.

Aliada à pedagogia e à didática está a avaliação do ensino e aprendizagem, disciplina bastante marginalizada da formação de professores para o magistério jurídico, como evidenciado nos dados colhidos anteriormente.

A lista de disciplinas mencionadas é exemplificativa. Muitas outras poderiam ser mencionadas, como filosofia da educação, currículo e até mesmo projetos integradores. Se faz necessário, portanto, repensar a formação do professor de Direito. Isso poderia acontecer, primeiramente, com a inclusão na legislação de parâmetros mais claros para a formação do professor de Direito, alcançando-se a devida formação pedagógica. Isso levaria à inclusão, nos currículos dos programas de pós-graduação stricto sensu, de disciplinas voltadas ao ensino, como é o caso da avaliação da aprendizagem e de tantas outras necessárias a atuação em sala de aula. Desta forma, seria traçado um caminho possível para a melhoria da avaliação da aprendizagem e das práticas de ensino nestes cursos.

\section{CONCLUSÃO}

A avaliação da aprendizagem ocupa um lugar periférico na formação do professor dos cursos de Direito no Nordeste. Apenas três dos programas analisados incluíram o estudo da avaliação em suas ementas e, mesmo assim, de forma superficial e com cargas horárias insuficientes, com disciplinas que não conseguem abarcar o conjunto de saberes que se fazem necessários a atuação docente.

Torna-se essencial que o professor de Direito tenha formação no campo pedagógico. Para isto, os programas de pós-graduação precisam compreender a necessidade de disciplinas como avaliação, didática, currículo, dentre outras, em cargas horárias compatíveis com as competências e habilidades que essas disciplinas oferecem.

Se a legislação sobre a matéria pouco ou nada dispõe sobre essa necessidade no currículo dos cursos de pós-graduação em Direito, torna-se necessário refletir sobre o papel das disciplinas 
relacionadas aos saberes docentes para quem atua no magistério dessa área, pois o domínio de conteúdos jurídicos não é suficiente para formar bons professores.

Também não se pode afirmar que há uma relação determinística entre a melhoria do currículo dos programas de pós-graduação em Direito e a atuação dos professores em sala de aula, pois as atuais políticas públicas para o ensino superior não têm se preocupado com a qualidade da educação, tampouco têm realizado sua função regulatória de garantir a qualidade do ensino superior.

$\mathrm{Na}$ verdade, existe um grande abismo entre o padrão de educação superior buscado na legislação e a realidade. Mesmo diante da ampliação do acesso ao ensino superior, hoje ainda existem inúmeros problemas relacionados à qualidade dos cursos oferecidos. Isso tem contribuído para um afastamento substancial destes cursos da realidade social, o que tem levado à formação de profissionais acríticos e individualistas e ao aprofundamento de um contexto de desigualdade.

Portanto, torna-se urgente que sejam realizadas reflexões sobre a formação dos professores de Direito, para que esse quadro seja alterado em prol da melhoria do ensino. A avaliação não pode reproduzir um modelo de ensino tradicional, com viés positivista. Ao contrário, deve servir ao processo de ensino e aprendizagem. Basta, para isso, que uma mudança comece acontecer na estrutura desses cursos, reconhecendo-se que a figura central desse processo é o aluno, que tem direito a uma educação de qualidade, verdadeiramente crítica e emancipadora.

\section{REFERÊNCIAS}

ABIKAIR NETO, J. A importância da formação pedagógica dos professores de direito: benefícios e possibilidades para o seu melhoramento. Revista Derecho y Cambio Social, Lima, v. 37, p. 2-19, 2014.

ADEODATO, J. M. L. Bases para uma metodologia da pesquisa em Direito. Revista CEJ, Brasília, v. 7, n. 1, p. 143-150, 1999.

ALTHUSSER, L. Aparelhos ideológicos de Estado. 2. ed. Rio de Janeiro: Graal, 1985.

AMARAL, N. C. As Universidades Federais brasileiras sob ataque do Governo Bolsonaro.
Revista Propuesta Educativa, Buenos Aires, v.2, n. 52, ano 28, p. 127-138, 2019.

BASSO, G. Capes estuda novos congelamentos após cortes de $\mathbf{7 0} \%$ para novas bolsas em junho. Santos, 2019. Disponível em: https://revistaforum.com.br/brasil/capes-estudanovos-congelamentos-apos-cortes-de-70-paranovas-bolsas-em-junho/. Acesso em 19 dez.2019

BRASIL. Lei no 9394, de 20 de dezembro de 1996. Dispõe sobre as Diretrizes e Bases da Educação Nacional (LDB). Brasília, DF: Presidência da República, Casa Civil, dez. 1996. Seção 1, p. 1.

BRASIL. Lei no 10.861, de 14 de abril de 2004 . Dispõe sobre o Sistema Nacional de Avaliação do Ensino Superior (SINAES). Brasília, DF: Presidência da República, Casa Civil., abr. 2004. Seção 1, p. 1.

BRASIL. Ministério da Educação. SINAES/DAES. Instrumento de avaliação de cursos de graduação presencial e a Distância - autorização. Brasília: MEC, 2017a.

BRASIL. Ministério da Educação. SINAES/DAES SINAES/DAES. Instrumento de avaliação de cursos de graduação presencial e a Distância reconhecimento e renovação de reconhecimento. Brasília: MEC, 2017b.

BRASIL. Resolução CNE/CES no 5, de 17 de dezembro de 2018. Dispõe sobre as Diretrizes Nacionais Curriculares (DCN) dos cursos de Direito. Diário Oficial da União. Brasília, DF, dez. 2018. Seção 1, p. 122.

BRASIL. Resolução CNE/CES no 9/2004. Dispõe sobre as Diretrizes Nacionais Curriculares (DCN) dos cursos de Direito. Portal do MEC. Brasília, DF, set. 2004. Seção 1, p. 1.

BRASIL. Portaria Normativa no 23, de 21 de dezembro de 2017. Dispõe sobre os fluxos dos processos de credenciamento e recredenciamento de instituições de educação superior e de autorização, reconhecimento e renovação de reconhecimento de cursos superiores, bem como seus aditamentos. Diário Oficial da União. Brasília, DF, dez. 2017. Seção 1, p. $44-49$.

CAPELLARI, E.; PRANDO, F. C. M. (Orgs.). Ensino jurídico: Leituras interdisciplinares. São Paulo: 
Cultura Paulista, 2001.

CAPES. Programas e cursos de Pós-Graduação em Direito no Brasil. Brasília, 2020a. Disponível em:

https://sucupira.capes.gov.br/sucupira/public/co nsultas/coleta/programa/quantitativos/quantitati voAreaConhecimento.jsf?areaAvaliacao=26.

Acesso em: 17 jun. 2020.

CAPES. Programas e cursos de Pós-Graduação em Direito no Nordeste. Brasília, 2020b. Disponível em: https://sucupira.capes.gov.br/sucupira/public/co nsultas/coleta/programa/quantitativos/quantitati voBuscaAvancada.jsf. Acesso em: 17 jun. 2020.

CARVAlho, C. H. A. Política para a educação superior no governo Lula: expansão e financiamento. Revista do Instituto de Estudos Brasileiros, São Paulo, n. 58, p. 209-244, jun. $2014 . \quad$ Disponível em: http://www.revistas.usp.br/rieb/article/view/823 97 Acesso em: 17 jun. 2020. DOI: 10.11606/issn.2316-901X.v0i58p209-244

CASTANHO, D. M.; FREITAS, S. N. Inclusão e prática docente no ensino superior. Revista Educação Especial, Santa Maria, n. 27, p. 93-99, 2006.

CASTRO, L. M. C. A universidade, a extensão universitária e a produção de conhecimentos emancipadores. In: REUNIÃO ANUAL DA ANPED, 27., 2004, Caxambu. Anais... Caxambu, MG: ANPED, 2004, p. 1-16.

CUNHA, M. I. Diferentes olhares sobre as práticas pedagógicas no Ensino Superior: a docência e sua formação. Revista Educação, Porto Alegre, v. 54, n. 3, p. 525-536, set./dez. 2004.

CORDEIRO, C. P. B. S. 2019. Os desafios da avaliação da aprendizagem nos cursos de Direito. 2019. Tese (Doutorado em Educação) Faculdade de Educação, Universidade Federal de Alagoas, Maceió, 2019.

FADIC. Mestrado em Direito. Recife, 2020. Disponível em: https://www.faculdadedamas.edu.br/mestradoem-direito/\#focus. Acesso em: 17 jun. 2020.

FERREIRA, S. As políticas de expansão para educação superior dos governos do Partido dos Trabalhadores (2003-2016): inclusão e democratização? Revista Educação Unisinos, São Leopoldo, v. 23, n. 2, p. 257-272, abr./jun. 2019. Disponível em: http://revistas.unisinos.br/index.php/educacao/a rticle/view/15451. Acesso em: 17 jun. 2020. DOI: 10.4013/edu.2019.232.04

FUFSE. Documentos. Sergipe, 2020. Disponível em:

https://www.sigaa.ufs.br/sigaa/public/programa/ documentos.jsf?lc=pt BR\&id=717\&idTipo=1.

Acesso em: 17 jun. 2020.

GOMES, A. M. Política de Avaliação da Educação Superior: controle e massificação. Revista Educação e Sociedade, Campinas, v. 23, n. 80, p. 275-298, set. 2002. Disponível em: https://www.scielo.br/scielo.php?script=sci artte xt\&pid=S0101-

73302002008000014\&lng=pt\&tlng=pt. Acesso em: 17 jun. 2020. DOI:10.1590/S0101$\underline{73302002008000014}$

HAYDT, R. C. C. Avaliação do processo ensinoaprendizagem. São Paulo: Ática, 2004.

HAYDT, R. C. C. Curso de Didática Geral. São Paulo: Ática, 2006.

HOFFMANN, J. O jogo do contrário em avaliação. 9. ed. Porto Alegre: Mediação, 2014.

LAFOURCADE, P. D. Planejamento e avaliação do ensino: teoria e prática da avaliação do aprendizado. 2. ed. São Paulo: IBRASA, 2010.

LIBÂNEO, J. C. Formação de professores e didática para Desenvolvimento Humano. Revista Educação e Realidade, Porto Alegre, v. 40, n. 2, p. 629-650, abr./jun. 2015. Disponível em: https://www.scielo.br/scielo.php?script=sci artte xt\&pid=S2175-

62362015000200629\&Ing=pt\&tIng=pt. Acesso em: 18 jun. 2020. DOI: 10.1590/2175-623646132

LUCKESI, C. C. Avaliação da aprendizagem escolar. São Paulo: Cortez, 2002.

MACHADO, A. A. Ensino jurídico e mudança social. Campus de Franca: Unesp, 2009.

MELO, A. A. S.; SOUZA, F. B. A agenda de 
mercado e a educação no governo Temer. Revista Germinal: Marxismo e Educação em Debate, Salvador, v. 9, n. 1, p. 25-36, ago. 2017. Disponível em: https://portalseer.ufba.br/index.php/revistagerm inal/article/view/21619. Acesso em: 17 jun. 2020. DOI: 10.9771/gmed.v9i1.21619

MORAIS, J. L. B. de; SANTOS, A. L. C. O ensino jurídico e a formação do bacharel em Direito: diretrizes político-pedagógicas do curso de Direito da UNISINOS. Porto Alegre: Livraria do Advogado, 2007.

MURARO, C. C. A formação do professor de direito. Revista Âmbito Jurídico, Rio Grande, v. 13, n. 73, fev. 2010.

PALMEIRA. L. L. L. Direitos Humanos e Ensino Jurídico: uma articulação indissociável a formação cidadã. 2018. Tese (Doutorado em Educação) - Faculdade de Educação, Universidade Federal de Alagoas, Maceió, 2018.

PERRENOUD, P. Avaliação: da excelência à regulação das aprendizagens - entre duas lógicas. Tradução de Patrícia Chittoni Ramos. Porto Alegre: Artmed, 1999.

PIMENTA, S. G.; ANASTASIOU, L. G. C.; CAVALLET, V. J. Docência no ensino superior: construindo caminhos. In: BARBOSA, R. L. L. (Org.) Formação de professores: desafios e perspectivas. São Paulo: UNESP, 2003. p. 267-278.

PRADO, E. C. Pós-graduação stricto sensu em Direito: onde e como se forma o docente dos cursos de graduação. Revista Brasileira de PósGraduação, Brasília, v. 12, n. 28, p. 443-470, ago. 2015. Disponível em: http://ojs.rbpg.capes.gov.br/index.php/rbpg/arti cle/view/814. Acesso em: 17 jun. 2020. DOl: 10.21713/2358-2332.2015.v12.814

RODRIGUES, H. W. Ensino Jurídico e Direito Alternativo. São Paulo: Editora Acadêmica, 1993.

ROMÃO, J. E. Avaliação dialógica: desafios e perspectivas. 9.ed. São Paulo: Cortez, 2011.

UFAL. Mestrado em Direito. Maceió, 2020. Disponível em: http://www.ufal.edu.br/unidadeacademica/fda/p os-graduacao/mestrado-em-direito/. Acesso em
19 mai. 2020.

UFBA. Disciplinas. Salvador, 2020. Disponível em: https://ppgd.ufba.br/sites/ppgd.ufba.br/files/nov a grade curricular 2019 site.pdf/. Acesso em 19 mai. 2020.

UFC. Grade Curricular. Fortaleza, 2020. Disponível em: http://www.ppgdireito.ufc.br/public html/index. php/grade-curricular. Acesso em: 15 jun. 2020.

UFC. Regulamentos. Fortaleza, 2020. Disponível em:

http://www.ppgdireito.ufc.br/public html/index. php/regulamentos. Acesso em: 15 jun. 2020.

UFMA. Resoluções. São Luís, 2020. Disponível em:

https://sigaa.ufma.br/sigaa/public/programa/doc umentos stricto.jsf?|c=pt BR\&idPrograma=1161 \&idTipo=3. Acesso em: 15 jun. 2020.

UFMA. Regimento. São Luís, 2020. Disponível em: https://sigaa.ufma.br/sigaa/public/programa/doc umentos stricto.jsf?lc=pt BR\&idPrograma=1161 \&idTipo=2. Acesso em: 15 jun. 2020.

UFPB. Ementa das disciplinas. João Pessoa, 2020. Disponível em: http://www.ccj.ufpb.br/pos/contents/menu/ppg cj/ppgcj-2013-mestrado-e-doutorado/estruturacurricular-1/ementas-das-disciplinas. Acesso em: 15 jun. 2020.

UFPE. Regimento do programa de pósgraduação em Direito. Recife, 2020. Disponível em: https://www.ufpe.br/ppgd/documentos/Lasset publisher/VXbw86gxSj69/document/id/19 8639? inheritRedirect=false \& redirect=https\%3A\% 2F\%2Fwww.ufpe.br\%2Fppgd\%2Fdocumentos\%3F p p id\%3D101 INSTANCE VXbw86gxSj69\%26p p lifecycle\%3D0\%26p p state\%3Dnormal\%26p p mode $\% 3 D v i e w \% 26 p$ p col id\%3Dcolumn4\%26p p col count\%3D1. Acesso em: 15 jun. 2020.

UNI7. Ementário das disciplinas do Mestrado em Direito. Fortaleza, 2020. Disponível em: https://www.uni7.edu.br/wpcontent/uploads/2017/02/UNI7-EmentarioMestrado-em-Direito-Privado.pdf. Acesso em: 15 jun. 2020. 
UNI7. Coordenação do Programa de Mestrado em Direito divulga informações do processo seletivo 2016.1. Fortaleza, 2020. Disponível em: https://www.uni7.edu.br/noticia/coordenacaodo-programa-de-mestrado-em-direito-divulgainformacoes-do-processo-seletivo-20161/. $\quad 15$ jun. 2020.

UNICAP. Programa das disciplinas. Boa Vista, 2020. Disponível em: http://www.unicap.br/ppgd/index.php/oprograma/. Acesso em: 15 jun. 2020.

UNICHRISTUS. Metodologia da educação jurídica, avaliação e desenvolvimento. Fortaleza, $2020 . \quad$ Disponível em: https://unichristus.edu.br/metodologia-daeducacao-juridica-avaliacao-e-desenvolvimento/. Acesso em: 15 jun. 2020.

UNIFG. Disciplinas. Jaboatão dos Guararapes, $2020 . \quad$ Disponível em: http://faculdadeguanambi.edu.br/ppgdunifg/estr utura-curricular/disciplinas//. Acesso em: 15 jun. 2020.

UNIFOR. Programa de Mestrado e Doutorado em Direito Constitucional. Fortaleza, 2020. Disponível em: https://www.unifor.br/documents/392178/4301 23/ppgd guia regimento 2018.pdf/69cbcc988af7-82c1-5fb3-96af1d56bb3b. Acesso em: 15 jun. 2020.

UNIFOR. Programa de Mestrado Profissional em Direito e Gestão de Conflitos. Fortaleza, 2020. Disponível em: https://www.unifor.br/web/posgraduacao/mestrado-profissional-direito. Acesso em: 15 jun. 2020.

UNIT-SE. Documentos e formulários. Aracaju, $2020 . \quad$ Disponível em: https://ppg.unit.br/ppgd/paginas/documentos-eformularios. Acesso em: 15 jun. 2020.

SÔNEGO, A. Os desafios da universidade no Século XXI e algumas reflexões sobre a posição docente frente a este processo. Revista Brasileira de Ensino Superior, Passo Fundo, v.1, n. 1, p. 3035, jul./set. 2015. Disponível em: http://www.bibliotekevirtual.org/index.php/2013 -02-07-03-02-35/2013-02-07-03-03-11/1297rebes/v01n01/13703-os-desafios-dauniversidade-no-seculo-xxi-e-algumas-reflexoes- sobre-a-posicao-docente-frente-a-esteprocesso.html. Acesso em: 17 jun. 2020. DOl: 10.18256/2447-3944/rebes.v1n1p30-35

VEIGA, I. P. A. Aula universitária e inovação. In: VEIGA, I. P. A; CASTANHO, M. E. L. M. (Orgs.). Pedagogia Universitária: a aula em foco. Campinas: Papirus, 2000. p. 161-191.

VEIGA, I. P. A.; D'ÁVILA, C. M. Didática e docência na educação superior. Campinas: Papirus, 2019.

VIANNA, H. M. Avaliação educacional: Teoriaplanejamento-modelos. São Paulo: IBRASA, 2000. 